\title{
TÉCNICAS DE ANIMAÇÃO EM AMBIENTES TRIDIMENSIONAIS
}

\author{
Walter Dutra da Silveira Neto. M.Sc. ${ }^{1}$, Adrei Krepsky de Melo $^{2}$ \\ ${ }^{1,2}$ Grupo de Pesquisa de Modelagem Virtual, Universidade do Estado de Santa Catarina, Av. Madre Benvenutta, \\ 1907, Itacorubi, Florianópolis, SC, Brasil \\ walter@udesc.br
}

\begin{abstract}
Resumo - Este artigo faz um estudo dos princípios fundamentais de animação desenvolvidos na década de trinta aplicados no ambiente virtual da animação tridimensional contemporânea. Tais princípios foram identificados e um software de animação tridimensional foi escolhido. Foram desenvolvidos um ambiente e um contexto para animação. Os princípios foram testados e verificou-se uma aplicabilidade satisfatória devido à versatilidade do software.
\end{abstract}

Palavras Chave: (Animação, Modelagem, 3D)

\begin{abstract}
This paper makes a study of the fundamental principles of animation developed in the decade of thirty applied in the virtual atmosphere of the contemporary tridimensional animation. Such principles were identified and a software of tridimensional animation was chosen. It was developed an atmosphere and a context for animation. The principles were tested and a satisfactory applicability was verified due to versatility of the software.
\end{abstract}

Key-words: (Animation, Modelling, 3D)

\section{Introdução}

A animação de personagens ou "character animation", pode ter uma infinidade de significados como: cabos de vassouras ambulantes, ratos que falam, brinquedos que criam vidas e tudo que se pode imaginar no que se trata em dar vida a objetos.

Estes processos embora que gratificantes, levam horas para que se chegue a um resultado satisfatório, revisando, renderizando ${ }^{(1)}$, testando, reestruturando, acertando tempos precisos. Com o advento dos computadores pessoais, o acesso a essas técnicas de animação tridimensional em ambientes virtuais tornou-se muito mais acessível a todos, porém, chegar a uma produção de alta qualidade já não é tão simples assim, pois exige muito tempo no aprendizado de técnicas e maneiras ideais para que se chegue a um bom resultado gastando o mínimo em processamento.

$\mathrm{O}$ animador não só tem que ter a habilidade técnica de modelar ou ajustar o posicionamento dos personagens como também ter uma precisão em sincronizar, observar, e ajustar os movimentos dos objetos. Além disso, o animador também deve ter um senso de trazer um objeto inanimado a vida.

Este artigo tem como proposta, apontar os principais processos que envolvem uma animação desenvolvida por softwares tridimensionais.

\section{Metodologia}

Realizou-se um estudo sobre as técnicas convencionais de animação, bem como, os processos modernos de criação de movimento. Os princípios fundamentais da animação foram identificados e observados. O objeto de estudo foi definido como 0 universo da animação tridimensional, em virtude de seu uso extremamente difuso no design. Definiu-se que o software utilizado para testar tais princípios seria o 3D Studio Max, da Discreet, em razão da compatibilidade com os sistemas disponíveis, e, em razão de sua grande versatilidade.

\section{Técnicas Utilizadas}

\section{Modelagem}

Para a realização de um projeto de animação tridimensional, diversos métodos de modelagem são utilizados.

\footnotetext{
${ }^{1}$ Em computação, renderizar é o processo utilizado pelo computador para gerar uma imagem a partir das propriedades atribuídas em uma cena.
} 
Cada forma de modelagem possui características que podem facilitar a construção de determinada geometria, Boardman [1].

Atualmente, os métodos de modelagem oferecidos pela maior parte dos softwares de modelagem tridimensional, de acordo com Lucena [2], podem ser divididos em cinco categorias:

- Formas primitivas

- Modelagem de Forma Livre

- Geometria Sólida Construtiva, ou CGS ${ }^{(2)}$

- Modelagem por Procedimento

- $\quad$ Modelagem por Derivação

As primitivas geométricas constituem uma coleção de formas pré-construídas, que possuem diversos parâmetros de configuração formal. As geometrias mais comuns são: a esfera, o cubo, o cilindro e o cone, porém, cada software pode oferecer sua diversidade de primitivas.
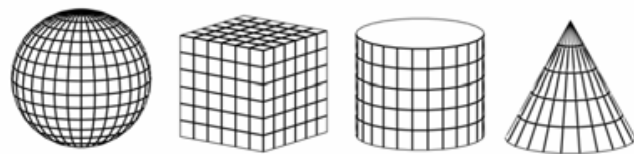

Figura 1 - Primitivas Geométricas

As possibilidades de manipulação da geometria, através de pontos de controle de suas curvas, caracterizam a Modelagem de Forma Livre, uma vez que permite ao usuário trabalhar com pontos isolados da malha ou em conjunto desses pontos.
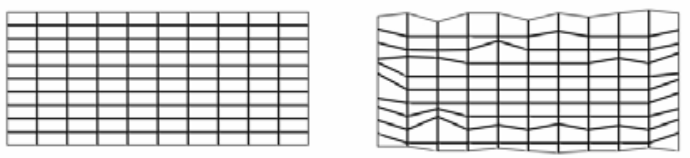

Figura 2 - Modelagem de Forma Livre.

Outra forma de modelagem, a de Geometria Sólida Construtiva, faz uso de operações de união, intersecção e diferença entre duas geometrias, para a geração de novas formas tridimensionais, chamadas de operações booleanas.
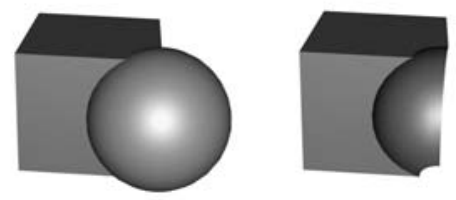

Figura 3 - Operações booleanas.
A modelagem por procedimento, faz uso de um determinado algoritmo, não para definir exatamente a geometria de um objeto, mas para atribuir um tipo de procedimento, ou ação, que irá definir como um objeto será gerado. Para o procedimento utilizado, podese ter diversos parâmetros a serem configurados, o que possibilita uma facilidade de modificação das características formais do objeto.

O método de modelagem por derivação, pode ser subdividido em três outras formas de geração de modelos tridimensionais, porém todas realizam relações entre duas ou mais formas bidimensionais para a criação de um objeto 3D:

$\begin{array}{ll}\text { - } & \text { Extrusão } \\ \text { - } & \text { Secção Transversal Serial } \\ & \text { O métododo de Extrusão permite que uma }\end{array}$ cópia da forma bidimensional seja estendida ao longo de um eixo espacial selecionado.
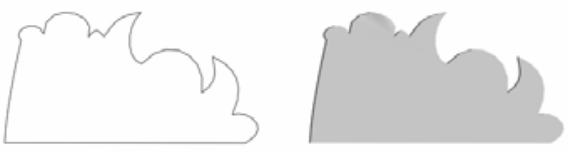

Figura 4 - Extrusão

Uma variante do conceito de extrusão, a Modelagem por Secção Transversal Serial, permite a conexão de diversas secções bidimensionais que podem ter diversas formas e tamanhos. Este processo é útil para a criação de formas orgânicas, como, por exemplo, seres humanos, uma vez que estas formas são facilmente descritas por uma série de contornos bidimensionais.

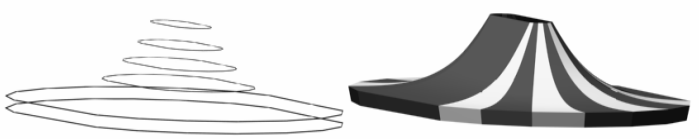

Figura 5 - Modelagem por Secção Transversal Serial.

$\mathrm{Na}$ última técnica de modelagem por derivação, a de Revolução, o software realiza um giro completo em torno do próprio eixo de uma forma bidimensional.

2 A "CGS" é um termo utilizado para a modelagem de sólidos, que define complexos sólidos pela composição de sólidos simples (primitivas) e/ou objetos já combinados, até que se chegue a um objeto mais complexo. 


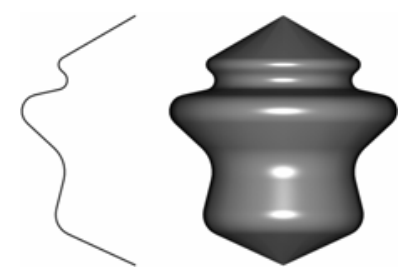

Figura 6 - Modelagem por revolução

\section{Renderização}

Após a construção de todos os modelos tridimensionais, da definição das câmeras e fontes de iluminação, do processo de definição das características da superfície de cada objeto, além da animação dos personagens, todos os elementos que compõe a animação já estão completos. Numa etapa posterior, é necessário que todos esses parâmetros sejam calculados e transferidos para uma imagem final bidimensional, ou mesmo para uma seqüência de imagens bidimensionais, no caso de uma animação. É interessante perceber que, a tridimensionalidade de uma imagem realizada em 3D é ilusória, uma vez que tanto o processo de criação, no ambiente do software, quanto a imagem final, estão atrelados à um plano bidimensional, seja ele um monitor, um papel, uma película, etc.

Em síntese, ao se realizar uma renderização, todos os parâmetros citados anteriormente são processados para gerar uma imagem final. Para que esta imagem seja realizada, de acordo com Kerlow [3], existem três métodos de renderização que podem ser utilizados:

\section{- Z-Buffer \\ - Ray Tracing \\ - Radiosity}

No primeiro método, o de Z-Buffer, os objetos da cena são distribuídos levando em consideração seus parâmetros de profundidade na cena, que são armazenados num buffer ${ }^{(3)}$, para verificar se determinado ponto de cada objeto é visível em relação à câmera.

O segundo método, o de ray tracing, realiza um cálculo dos trajetos, no ambiente tridimensional, dos raios emitidos por determinada fonte de luz, até o ponto de vista da câmera, com este método torna-se possível visualizar o efeito de fontes de luz, uma vez que o método de Z-buffer não levaria em consideração 0 trajeto dos raios luminosos que estavam sendo emitidos do interior de um material transparente.
O método de radiosity calcula a transferência de quantidade de luz entre as superfícies de todos os objetos envolvidos na renderização até que a energia de luz seja totalmente absorvida pelas superfícies, ou dissipada pelo espaço. Pode-se perceber que este método calcula a direção dos raios de luz entre todas as direções possíveis para todo o ambiente envolvido, diferente do método de ray tracing, que calcula apenas a direção dos raios entre a câmera e a fonte de luz.

\section{Animação}

\section{animação. \\ Os 12 princípios fundamentais de}

A Walt Disney Productions [4] foi responsável por formalizar os princípios básicos da animação clássica elaborados para a execução do primeiro longa-metragem animado do cinema, "Branca de Neve e os Sete Anões" (1937). Eles fazem parte de um conjunto de informações que um animador deve possuir - independente da técnica adotada para a síntese de movimento de personagens.

Estes princípios determinam as regras para a análise e criação de ações e gestos na animação clássica e são descritas abaixo:

\section{Timing (temporização):}

A relação de tempo obviamente é a essência de uma animação. A velocidade a qual algo se movimenta dão um senso do que o objeto é e por que está movimentando-se. Algo como um piscar de olho, pode ser rápida ou lenta. Se for rápido, o personagem parecerá alerta e despertará. Se for lenta poderá parecer cansado e letárgico.

\footnotetext{
3 Buffer é um dispositivo de armazenagem temporária usado para compensar as diferenças na taxa de dados e o fluxo de dados entre dois dispositivos (tipicamente um computador e uma impressora). Também é chamado de Spooler.
} 
Os personagens utilizados na criação dos cartoons normalmente são caracterizados como cronometragens rápidas entre uma pose e outra, as animações reais tendem a ter suas cronometragens mais lentas fazendo com que a torne verdadeira, portanto, manter a concatenação dos eventos e sua coerência temporal, são fundamentais para a autenticidade da narrativa.

As relações de tempo conferem veracidade à animação.

\section{Slow-in and Slow-out (Suavização do início e do fim)}

O princípio das seqüências e seu término devem ter sua construção cadenciada, permitindo ao espectador se ajustar às mudanças de cada cena nova.

Por exemplo, uma bola saltando tende a ter uma velocidade maior quando está caindo do que quando está subindo, isso deve-se a fato de que temos uma força de gravidade atuando sobre a mesma.

\section{Arcs (arcos)}

No mundo real quase todas as ações são feitas através de linhas precisas e harmoniosas que permitem uma suavização dos movimentos.

Quando criamos animações construímos movimentos que percorrem uma trajetória, seguem caminhos curvos em lugar de lineares. Muito raramente é que um personagem ou parte de um personagem movimentam-se em linhas retas. Até mesmo o movimento dos personagens tendem a não seguir caminhos lineares. Quando um braço tenta alcançar algo seu movimento tende mudar-se para um arco.

\section{Anticipation (antecipação)}

As ações em uma animação normalmente acontecem em três seções: A organização do movimento, a ação atual e então o seguimento da ação. A primeira parte é conhecida como antecipação. Em alguns casos a antecipação fisicamente é essencial.
Por exemplo, antes que você possa lançar uma bola você tem que balançar seu braço para trás, essa ação do braço é a antecipação, enquanto que o lançamento é o próprio movimento. A antecipação é usada para chamar a atenção do espectador para prepará-lo na ação que segue. Um período mais longo da antecipação geralmente é necessário para ações mais rápidas.

Geralmente nas animações mais realistas o espectador tem que imaginar o que deverá acontecer (antecipação), o que está acontecendo (a própria ação atual) e o que aconteceu (o resultado final).

\section{Exaggeration (exagero)}

O exagero é usado para acentuar uma ação. Deve ser usado de maneira cuidadosa e equilibrada, não arbitrariamente, o resultado deverá ser uma animação realística e divertida. Os exageros, as anormalidades de dimensões, a desproporção são mais apropriadas para animar personagens caricatas.

\section{Squash and Stretch (esmague e estique)}

A distorção dos personagens ou dos objetos em uma cena acentua o movimento e o realismo da animação. Princípios físicos como inércia, peso ou velocidade também podem ser "deformados" para realçar algum aspecto da trama e para criar maior tensão, por exemplo, se uma bola de borracha salta e bate o chão, a mesma sofre uma força fazendo com que seu corpo seja esmagado.

O uso mais óbvio deste princípio na animação de personagens é a contração de seus músculos, quando são contraídos automaticamente deverão ser esmagados e quando estendidos, esticados.

Objetos rígidos, de certo modo, ainda podem ser esmagados e/ou esticados, pense em um objeto que possua em seu corpo dobras, como uma luminária, seu corpo é rígido, mas se quisemos animá-la saltitando, seu corpo deverá ser esmagado e 
esticado, respeitando suas engrenagens.

\section{Secondary Action (ação secundária)}

A ação secundária faz com que a animação fique mais interessante e ao mesmo tempo cria um aspecto mais realista, ou seja, se um personagem caminha numa animação, ele movimenta não só as pernas, mas a cabeça e os braços.

8. Follow Through and Overlapping Action (ação de seguimento e ultrapassagem)

Os princípios físicos em uma animação conferem autenticidade ao filme e mantêm o espectador identificado com os personagens. Uma das recomendações é manter a ação fluída, sem interrupções abruptas de movimentos. Um exemplo claro pode ser visto numa seqüência de perseguição em que um carro da uma freada brusca e a câmera tenha um comportamento inercial, perdendo o enquadramento momentaneamente.

\section{Straight Ahead Action and Pose-to-} Pose Action (diretamente $x$ quadro-aquadro)

A cena pode ser construída e editada de maneira fluída, sob a forma de um passeio da câmera, ou em tomadas quadro a quadro, quebrando a continuidade de uma seqüência, mas enfatizando algum elemento em especial.

\section{Staging (enquadramento)}

O universo da animação não apresenta restrições para a posição ou para o ângulo em que uma tomada é realizada. Entretanto, é necessário atentar para a capacidade do espectador de entender o ambiente mostrado. Desta forma, devem-se evitar mudanças de enquadramento que não sejam somadas nas tomadas anteriores ao processo de construção da cena. O principal é dar ênfase a ação.

\section{Appeal (apelo)}

Um personagem de animação cativa 0 público por suas características reais e humanas. Este é o apelo de um personagem, sua capacidade de atingir o espectador e de se relacionar com ele.

Esta qualidade pode estar também ligada ao seu charme, forma, simplicidade, comunicação ou magnetismo, o apelo pode ser atingido utilizando outros princípios, como: exagero nas suas formas, respeitando suas simetrias, como também, usar aposição nas suas atitudes.

\section{Personality (personalidade)}

Este não pode ser considerado um princípio da animação, mas recorre à aplicação correta dos outros princípios. A personalidade de um determinado objeto ou criatura determina o sucesso de sua animação, a idéia é que o animador faça com que o personagem realmente pareça estar vivo criando personalidades diferentes a cada elemento de uma animação.

\section{Técnicas de Animação}

De acordo com Maestri [5], Jones e Bonney [6], uma das técnicas de computação gráfica mais comum na criação de uma animação é denominada de interpolação de quadros chaves. Através da interpolação automatizada entre quadros chaves, o usuário tem a possibilidade de definir somente alguns posicionamentos, ou quadros chaves, para determinado objeto da cena, e, a partir desses quadros chaves, o computador gera todos os quadros intermediários.

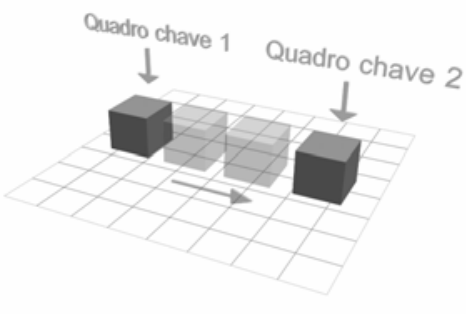

Figura 7 - Interpolação de Quadros Chaves 
Cada objeto da cena pode conter uma diversidade de parâmetros que podem ser utilizados para configurar um novo quadro chave. Esses parâmetros podem estar relacionados com uma simples mudança de posição espacial, até uma complexa mudança da geometria do objeto, enfim, cada software de animação tridimensional pode disponibilizar diversas ferramentas para alterar parâmetros de cada geometria. A interpolação entre quadros chaves é uma solução interessante para os animadores, uma vez que eles não precisam se preocupar com as minuciosas mudanças entre cada quadro de uma animação, ao contrário, os animadores podem estar focando seu trabalho nos quadros mais relevantes para a expressão da animação, deixando que os demais quadros, entre os quadros chaves, sejam automaticamente calculados.

A técnica de interpolação pode ser dividida em dois padrões de curvas, onde o primeiro padrão, o de interpolação linear, corresponde a uma velocidade constante entre quadros chaves, e o segundo padrão, o de interpolação por curvas, proporciona diversos parâmetros que podem alterar a velocidade da interpolação de quadros entre quadros chaves. Tanto a interpolação linear quanto a interpolação por curvas podem ser representadas por gráficos chamados curva de parâmetros.

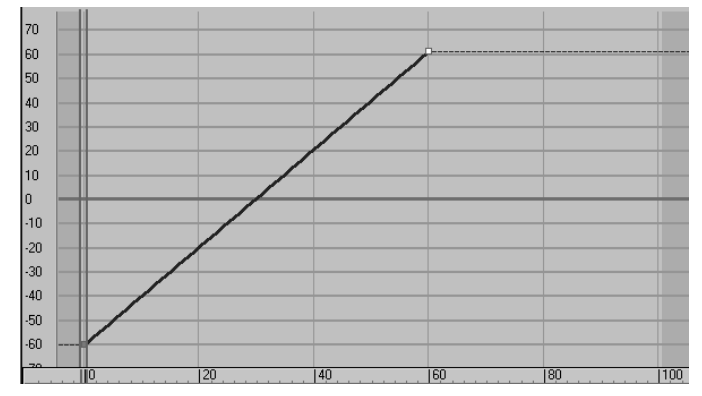

Figura 8 - Gráfico de Interpolação Linear

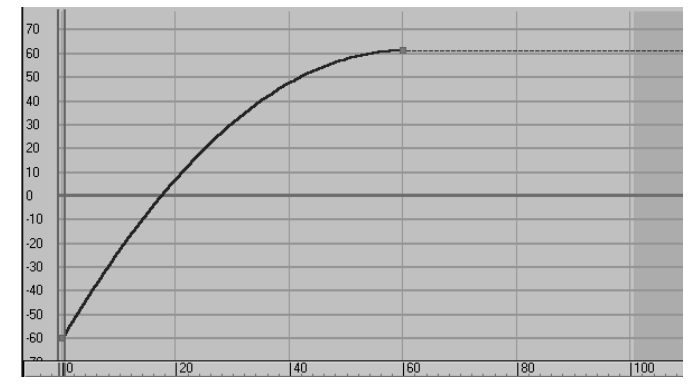

Figura 9 - Gráfico de Interpolação por Curvas
Outra técnica de animação, conhecida como forward kinematics a qual segundo Matossian [7], consiste na configuração da ação e da posição final do modelo, através da especificação dos ângulos das juntas. A forward kinematics consiste numa estrutura de hierarquia, onde cada objeto possui um nível de importância, fazendo com que todos os demais objetos de nível inferior na hierarquia acompanhem suas modificações de dimensionamento, translação e rotação.

Para o exemplo abaixo pode-se observar que qualquer movimento realizado no membro de número 1 , ou seja, o de maior importância hierárquica, estará influenciando todos os demais níveis inferiores da hierarquia. Em outro exemplo, as modificações na palma da mão, membro de número 7, irão influenciar apenas os membros de nível 8.

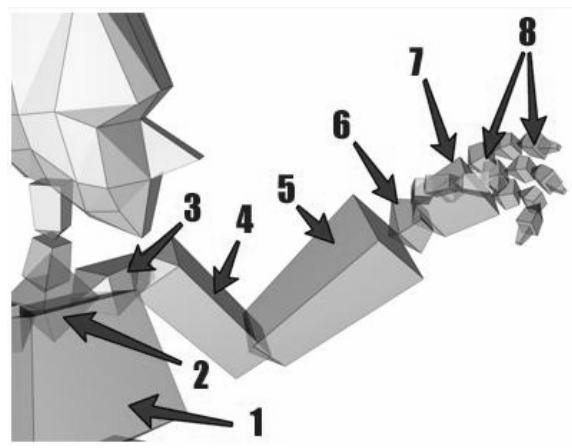

Figura 10 - Forward kinematics

Outra técnica, denominada inverse kinematics, tem como característica básica a sua inversão hierárquica, ao contrário da técnica de forward kinematics, fazendo com que o elemento de menor nível hierárquico atue como o de maior nível, controlando os elementos de nível superior.

As duas técnicas anteriores são largamente utilizadas para realizar a animação de esqueletos, que por sua vez são utilizados para animar personagens. Esta ferramenta proporciona uma geração automática de esqueletos inteligentes, com a possibilidade de personalização dos detalhes estruturais do esqueleto, como por exemplo, o número de dedos de uma mão.

Existem ainda dois modos de animação, sendo que no primeiro, o de forma livre, há a possibilidade de uso de forward e inverse kinematics (IK) para o posicionamento do esqueleto, enquanto que no segundo modo, o de animação automática, há 
possibilidade de se realizar uma animação baseada em pegadas, para isso utiliza-se o plugin $^{(4)}$ Character Studio exemplificado na figura abaixo.

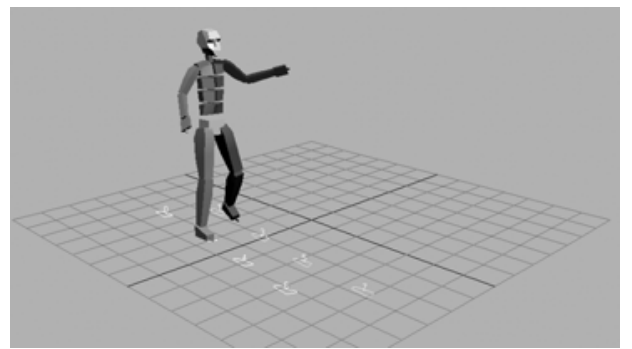

Figura 14 - character studio

\section{Resultados}

Utilizando as ferramentas de modelagem e animação tridimensional, foi verificado que os princípios de animação desenvolvidos na década de 20, sobretudo nos estúdios Disney, podem ser aplicados na animação tridimensional de maneira análoga e utilizados nos processos de animação tradicionais, uma vez que os softwares disponíveis oferecem tais recursos. Também se pôde verificar que tais princípios, apesar de terem sido desenvolvidos a cerca de seis décadas, ainda hoje são seguidos no intuito de conferir legibilidade às animações desenvolvidas.

\section{Discussão}

Apesar da tecnologia envolvida no processo de animação estar em constante processo de aprimoramento, considerando todas as ferramentas que hoje se encontram a disposição do animador, como os supercomputadores e os softwares de renderização, os princípios fundamentais de animação que são usados hoje foram todos desenvolvidos entre os anos da década de trinta. De fato, até a década de oitenta, o processo técnico de produção de animação diferencia muito pouco daquele do começo do século passado. Até muito pouco tempo atrás, toda a animação era produzida sobre as folhas de acetato e celulose, segundo o modelo patenteado por John Bray em 1914, e atribuído a Earl Hurd.

Os grandes avanços realizados no campo da animação foram feitos dentro dos Estúdios Disney, na Hyperion Boulevard, em Hollywood. As animações criadas hoje utilizam os mesmos 12 princípios básicos desenvolvidos naqueles estúdios, pela sua aplicabilidade, independentemente da técnica usada.

\section{Conclusão}

O presente trabalho verificou que apesar do processo de criação de animações ser quase tão antigo quanto o próprio cinema, a utilização de ferramentas de modelagem tridimensional nesse campo ainda é bem recente. Como este tipo de animação é diferente da animação tradicional, existindo somente no plano virtual, em forma de dados de computador que simulam a ação, o processo de desenvolvimento e criação assume outro caráter. A tarefa é simplificada, os resultados são mais facilmente obtidos, e um número maior de simulações pode ser realizado. $O$ resultado de tal atividade, entretanto, ainda deve se adequar ao repertório de associações que o seu expectador é capaz de efetuar. Para tanto, é fundamental que o produto final de tal técnica siga princípios que o expectador tenha consagrado.

\section{Referências Bibliográficas}

1. BOARDMAN, Ted. Desvendando o 3D Studio Max 3 - Modelagem, Materiais e Renderização, São Paulo: Editora Campus, 1999.

2. LUCENA, Alberto. Arte da animação. Técnica e estética através da história. São Paulo: SENAC, 2002.

3. KERLOW, Isaac Victor. The art of 3-D computeranimation an imaging. Milton, Australia: John Wiley \& Sons, 2000.

4. THOMAS, Frank e JOHNSTON, Ollie, Disney Animation: The Illusion of Life. New York: Walt Disney Productions, 1981.

5. MAESTRI, George. Animação Digital em 3D. São Paulo: Editora Market Books, 1999.

6. JONES, Angie e BONNEY, Sean. Animação Profissional com 3D Studio Max 3. Rio de Janeiro: Ciência Moderna, 2001.

7. MATOSSIAN, Michele, 3ds Max para Windows, São Paulo: Editora Campus, 2001. 